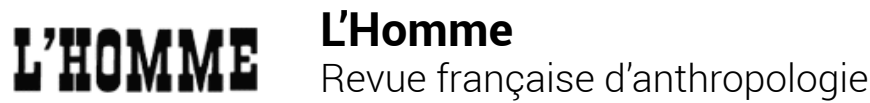

158-159 | avril-septembre 2001

Jazz et anthropologie

\section{Techniques \& culture, juil.-déc. 1999, 34 : Soieries médiévales, Sophie Desrosiers (ed.)}

Paris, Éditions de la Maison des sciences de l'homme, 207 pages

\section{Monique Lévi-Strauss}

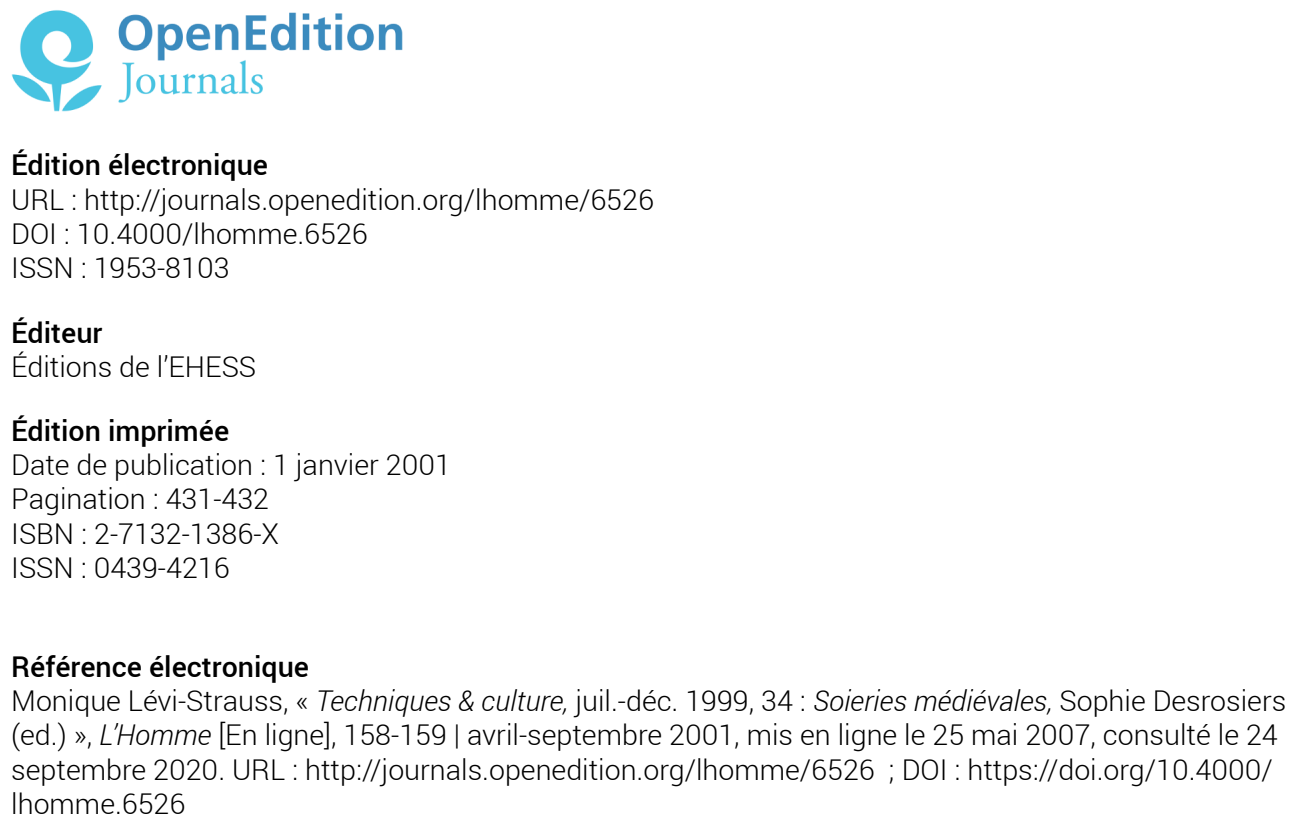

Ce document a été généré automatiquement le 24 septembre 2020.

(c) École des hautes études en sciences sociales 


\section{Techniques \& culture, juil.-déc. 1999, 34 : Soieries médiévales, Sophie Desrosiers (ed.)}

Paris, Éditions de la Maison des sciences de l'homme, 207 pages

Monique Lévi-Strauss

\section{RÉFÉRENCE}

Techniques \& culture, juil.-déc. 1999, 34 : Soieries médiévales, Sophie Desrosiers, ed. Publié avec le concours du CNRS, de l'Université René Descartes et du CNL, avec le soutien de l'Association pour l'étude et la documentation des textiles d'Asie (Paris) et de la Fondation Abegg (Riggisberg, Suisse). Paris, Éditions de la Maison des sciences de l'homme, 207 p., gloss., tabl., graph., ph.

1 TROUVÉES dans les tombes, conservées dans les trésors d'églises et dans des collections publiques ou privées, les soieries du Moyen Âge tardif (de la fin du $\mathrm{x}^{\mathrm{e}}$ siècle au début du $\left.\mathrm{XIV}^{\mathrm{e}}\right)$ nous disent rarement leur date et leur lieu de naissance. Depuis une quarantaine d'années, grâce au Centre international pour l'étude des textiles anciens (CIETA), un certain nombre de chercheurs ont tenté de conjuguer leurs efforts pour résoudre les énigmes que posaient les soieries médiévales. Douze d'entre eux, appartenant à des disciplines différentes, publient les résultats de leurs enquêtes.

2 Jane Merritt (chap. I) analyse 200 fragments datant de la période bouyide (IX ${ }^{\mathrm{e}}$ XIII ${ }^{\mathrm{e}}$ siècle) provenant des fouilles de Ravy, en Iran. Les tissus en coton, coton et soie ou soie pure présentent l'avantage de pouvoir être datés par association avec le mobilier archéologique. Donald King (chap. II) s'intéresse à la catégorie des tissus "diasprés ", soieries monochromes façonnées à petits motifs, apparues dès le $x^{e}$ siècle. Au XIV ${ }^{e}$ siècle, le terme se serait étendu aux soieries polychromes de même décor. La discussion de King est d'ordre linguistique. Hero Granger-Taylor (chap. III) analyse trois soieries trouvées dans la tombe de l'empereur Henry IV à Palerme (avant 1215) et 
conservées au British Museum. Le terme «taffetas lancé » précède celui de lampas : les trois soieries en question, de provenances différentes, illustreraient, entre autres, les trois étapes qui menèrent au lampas.

3 Se fondant sur des données stylistiques, Rosa Maria Martín i Ros (chap. IV) attribue les diverses soieries qui composent les vêtements liturgiques de saint Valère, conservés au Museu Tèxtil i d'Indumentaria de Barcelone, à des ateliers hispano-mauresques du XIII ${ }^{\mathrm{e}}$ siècle, cependant que Gabriel Vial (chap. V), après une étude technique poussée de ces mêmes textiles, souligne leur importance qui permet de comprendre le passage des tissus taquetés façonnés aux lampas.

4 Suivent deux chapitres (VI et VII) sur les «draps d'arest ». Donald King cherche l'étymologie du terme dans " arête de poisson », car le fond de ces tissus est à chevrons ou à losanges (formés par des bandes de chevrons régulièrement inversés). Après avoir recensé les 116 exemples connus de draps d'arest, Sophie Desrosiers les divise en deux groupes: les plus raffinés, tissés en Espagne, et les autres, produits au nord des Pyrénées. Elle se demande si ces derniers ne seraient pas également des « draps d'Alès » (le $r$ liquide permettant d'identifier l'appellation au nom de la ville) mentionnés dans les documents de l'époque.

5 Daniel De Jonghe et Chris Verhecken-Lammens (chap. VIII) examinent « une soierie losangée à bandes de samit façonné » et concluent que ce type de soierie était tissé endroit dessus sur un métier à la tire sans marches. Dominique Cardon (chap. IX) se penche sur deux fragments de soieries attribués à des provenances et des époques différentes et conservés dans le Trésor de la cathédrale de Carcassonne. Elle constate qu'il s'agit des deux morceaux restants d'un même tissu à fond losangé orné de bandes de samit façonné qui s'apparente aux draps d'arest. Enfin, elle émet l'hypothèse qu'il existait un centre de production pour ce genre de tissus dans le sud de l'Italie, alors sous l'influence de la Couronne d'Aragon. Dans deux soieries médiévales de même type, Witold Nowik (chap.X) identifie les produits tinctoriaux utilisés. Walter Endrei (chap. XI) étudie le métier de grande largeur à tisser la soie utilisé au XIII ${ }^{\mathrm{e}}$ siècle.

6 L'importation des soieries en Angleterre est bien attestée dans les sources écrites à partir de la fin du XII ${ }^{e}$ siècle. Frédérique Lachaud (chap. XII) a donc pu dépouiller les inventaires des trésors d'églises et la comptabilité des maisons aristocratiques anglaises, lesquelles fournissent des informations particulièrement riches quant aux soieries importées au XIII ${ }^{e}$ siècle et permettent souvent de connaître leurs lieux de fabrication.

7 Que l'approche soit matérielle, technique, stylistique, linguistique ou économique, ces études font mieux comprendre comment l'art de tisser la soie se répandit autour des rives occidentales de la Méditerranée au Moyen Âge. En incitant à se poser des questions plus précises, elles ouvrent de nouvelles pistes. En conclusion, on notera le remarquable travail éditorial de Sophie Desrosiers.

8 Il faut enfin rendre un dernier hommage à Krishna Riboud, disparue en juin 2000, à qui revient le mérite d'avoir organisé dans son centre, l'Association pour l'étude et la documentation des textiles d'Asie (AEDTA), en septembre 1993, le séminaire qui réunissait les auteurs du présent ouvrage et leur a permis de confronter leurs problèmes, sinon communs, du moins complémentaires. 


\section{AUTEURS}

\section{MONIQUE LÉVI-STRAUSS}

Paris 